\title{
ЦЕЛИ И ИЗМЕРИТЕЛИ УСТОЙЧИВОГО РАЗВИТИЯ РЕГИОНА (НА ПРИМЕРЕ ЧЕЧЕНСКОЙ РЕСПУБЛИКИ)
}

\author{
(c) 2021 Ахмадов Аслан Русланович \\ главный специалист-эксперт отдела планирования и прогнозирования бюджета \\ Министерство финансов Чеченской Республики, Россия, Грозный \\ E-mail:mr.ahmadov.a@mail.ru \\ (C) 2021 Бурцева Татьяна Александровна \\ доктор экономических наук, профессор \\ Российский технологический университет - МИРЭА, Россия, Москва \\ E-mail: tbur69@mail.ru \\ (C) 2021 Сатуев Бекхан Бексолтович \\ проректор по стратегическому развитию и социальной работе \\ Чеченский государственный университет, Россия, Грозный \\ E-mail: satuev@mail.ru
}

Проблема измерения устойчивого развития на региональном уровне крайне актуальна, так как существуют международные стандарты оценки устойчивого развития, разработаны национальные критерии для России, но регионы России пока не включились в данную работу. По информации специалистов Росстата отчёт по устойчивому развитию представила только Ростовская область. Это может быть связано с тем, что перечень показателей устойчивого развития слишком обширный, причём эти показатели мало представлены в стратегических документах. Кроме того, не все цели устойчивого развития имеют информационную поддержку на региональном уровне. В связи с чем авторы предлагают факторы, цели и перечень показателей регионального устойчивого развития. На основе авторских разработок проведён краткосрочный мониторинг устойчивого развития Чеченской республики, который показал, что основные проблемы устойчивого развития республики связаны с социальной сферой. Выводы авторов подтверждают правильность дерева целей развития республики, реализуемое в рамках её стратегии социально-экономического развития.

Ключевые слова: устойчивое развитие, регион, мониторинг, измерители, комплексные показатели

\section{Введение}

В 2000 г. в декларации ООН, принятой на саммите тысячелетия, впервые сформулированы цели развития тысячелетия до 2015 г. [1] Они включали восемь целей, двадцать одну задачу и шестьдесят показателей. $\mathrm{K}$ сожалению, не удалось реализовать все цели развития, особенно в части здоровья матерей и новорождённых. В 2015 г. принята новая повестка развития и разработаны цели устойчивого развития (ЦУР), которые содержатся в «Повестке дня устойчивого развития ООН до 2030 года». ЦУР ООН носят общечеловеческий характер и предназначены для всех стран. Данные цели включают больше позиций: семнадцать целей, сто шестьдесят девять задач и двести тридцать два показателя. Например, заявлена такая цель как - добиться гендерного равенства через расширение прав и возможностей всех женщин и девочек. На дан- ный момент, по оценкам ООН гендерное неравенство в мире в области распределения доходов составляет 12,5\%, то есть доходы женщин ниже доходов мужчин на $12,5 \%$ в среднем по миру.

Росстатом в соответствии с резолюцией Генеральной Ассамблеи ОOH A/RES/71/313 от 6 июля 2017 г. по разработке национальных наборов показателей ЦУР, исходя из национальных приоритетов, местных условий и имеющегося статистического потенциала, разработан перечень национальных показателей достижения ЦУР. Национальный набор показателей ЦУР предназначен для осуществления контроля за достижением целей устойчивого развития на национальном уровне. В нем отражены национальные особенности и учтены задачи, определённые в Указе Президента Российской Федерации от 7 мая 2018 года № 204 «О национальных целях и стратегических задачах развития Рос- 
сийской Федерации на период до 2024 года», стратегических документах Правительства Российской Федерации, а также национальных и федеральных проектах.

«Только часть ЦУР ООН носит всеобщий характер и имеет актуальное значение для некоторых российских регионов» [2]. Целью статьи является разработка актуального набора показателей ЦУР на региональном уровне и разработка рекомендаций по реализации регионального мониторинга ЦУР.

\section{1. Измерители устойчивого развития}

Измерители развития на макроуровне активно применяются с первой половины XX века. Создатели международного статистического стандарта - системы национальных счетов (CHC), Кузнец (Kuznets), Леонтьев (Leontief) и Стоун (Stone) даже получили Нобелевскую премию [1]. В 1970-х годах идея создания общих для всех стран измерителей развития получила продолжение, сделаны попытки учесть нерыночные факторы и состояние окружающей среды, например, предложены мера экономического благосостояния (MEW), разработанная Нордхаусом и Тобином (NordhausandTobin (1973). В 1989 г. Г. Дейли и Дж. Кобб предложили рассчитывать Индекс устойчивого экономического благосостояния (ИУЭБ, англ.- Index of Sustainable Economic Welfare, ISEW), который включил в себя серию поправок к ВВП, учитывающих социальные и экологические факторы, а также использование природных ресурсов. В последствие Дж.Коббом был предложен еще один индикатор, способный заменить показатель ВВП - это генеральный индикатор прогресса (ГИП, англ.- General Progress Indicator, GPI)» [2], однако, комплексного альтернативного ВВП измерителя создано не было. А предлагаемые новые измерители рассчитывались не по всем странам, например, генеральный индикатор прогресса никогда не рассчитывался для России [1]. Таким образом, проблема измерения развития полностью не решена до сих пор даже на уровне стран, что же говорить о региональном уровне.

В 1987 г. опубликован доклад ООН «Наше будущее» [1], в котором впервые определено, что «устойчивое развитие есть развитие, удовлетворяющее потребности настоящего времени без ущерба для возможностей будущих поколений удовлетворять их собственные потребности», в 1990 г. ООН создала комиссию по устойчивому развитию, а в 1993 г. этой комиссией предложен первый набор показателей устойчивого развития стран. После чего национальные статистические службы стали реализовывать оценку устойчивого развития (например, Норвегия, Канада, Австралии, Швейцарии, Германии, Нидерландов, Новой Зеландии и Бразилии). Международные организации, такие как Европейский Союз, Евростат, ОЭСР, ЕЭК ООН и Всемирный банк также проводят оценку устойчивого развития стран. Методологически измерение устойчивого развития развивалось по трём основным направлениям: комплексные показатели(например, индекс устойчивого экономического благосостояния, подлинный индикатор прогресса, индекс экономического благосостояния, истинные сбережения, показатель устойчивых чистых выгод, индекс человеческого развития, индекс счастливой планеты и др.), наборы показателей и сателлитные счета(например, система экологоэкономического учета (СЭЭУ 2012).«С середины 1990-х годов все большее число национальных статистических служб и международных организаций стали использовать наборы показателей для оценки устойчивого развития» [1]. При таком подходе, многомерный характер устойчивого развития не сводится к одной оценке, он представлен широким спектром показателей, которые предоставляют информацию по различным аспектам устойчивого развития. В связи с чем разработка регионального набора ЦУР для его мониторинга является актуальной научной задачей.

2. Перечень целей и показателей устойчивого развития региона

На рисунке 1 представлены факторы-цели устойчивого развития региона в соответствии с принятым в России национальным набором ЦУР.

В соответствии с представленными факторами и целями разработан перечень показателей ЦУР региона (см. табл. 1). Табл. 1 содержит показатели, собираемые Федеральной службой государственной статистики, Минстроем России, Росавтодором, Роспотребнадзором, Рострудом и Казначейством России. Данные показатели выбирались на основе следующих принципов:

- наличие данных по субъектам России;

- известность и используемость в мировой научной аналитической практике при оценке устойчивого развития страны и региона;

- возможность реализации мониторинга устойчивого развития на основе выбранных показателей; 


\begin{tabular}{|c|}
\hline Социальное развитие \\
\hline Повсеместная ликвидация нищеты \\
\hline $\begin{array}{c}\text { Ликвидация голода, обеспечение } \\
\text { продовольственной безопасности и } \\
\text { улучшение питания и содействие } \\
\text { устойчивому развитию сельского } \\
\text { хозяйства }\end{array}$ \\
\hline $\begin{array}{c}\text { Обеспечение здорового образа } \\
\text { жизни и содействие благополучию } \\
\text { для всех в любом возрасте }\end{array}$ \\
\hline $\begin{array}{c}\text { Обеспечение всеохватного и } \\
\text { справедливого качественного } \\
\text { образования и поощрение } \\
\text { возможности обучения на } \\
\text { протяжении всей жизни для всех }\end{array}$ \\
\hline $\begin{array}{c}\text { Гражданско-правовое } \\
\text { развитие }\end{array}$ \\
\hline $\begin{array}{c}\text { Обеспечение гендерного равенства и } \\
\text { расширение прав и возможностей } \\
\text { всех женщин и девочек }\end{array}$ \\
\hline $\begin{array}{c}\text { Сокращение неравенства внутри } \\
\text { стран и между ними }\end{array}$ \\
\hline
\end{tabular}

\begin{tabular}{|}
\hline Экономическое развитие \\
Обеспечение доступа к \\
недорогим,надёжным, устойчивым \\
исовременным источникам энергии \\
для всех \\
\hline Содействие поступательному, \\
всеохватному и устойчивому \\
экономическому росту, полной и \\
производительной занятости и \\
достойной работе для всех
\end{tabular}

Укрепление средств осуществления и активизация работы в рамках

Глобального партнёрства в интересах устойчивого развития

\section{Инновационное и цифровое} развитие

Создание стойкой инфраструктуры, содействие всеохватной и устойчивой индустриализации и инновациям

\begin{tabular}{|c|}
\hline Экологическое \\
развитие
\end{tabular}

Рисунок 1. Группировка целей устойчивого развития по факторам (разработка авторов)

Таблица 1. Перечень показателей ЦУР для региона и их динамика для Чеченской республики

\begin{tabular}{|c|c|c|c|c|}
\hline № & ЦУР/показатели & 2017 & 2018 & 2019 \\
\hline 1 & \multicolumn{4}{|l|}{ Повсеместная ликвидация нищеты во всех ее формах } \\
\hline 1.1 & $\begin{array}{l}\text { Доля населения, живущего за национальной чертой бедности } \\
\text { Источник: Росстат }\end{array}$ & 20,7 & 20,5 & 20,7 \\
\hline 1.2 & $\begin{array}{l}\text { Доля расходов консолидированных бюджетов субъектов Российской } \\
\text { Федерации на социальную поддержку отдельных категорий граждан к } \\
\text { собственным доходам консолидированных бюджетов субъектов Россий- } \\
\text { ской Федерации (за исключением субвенций) } \\
\text { Источники: Росстат, Казначейство России }\end{array}$ & 2,8 & 3,2 & 2,9 \\
\hline 2 & \multicolumn{4}{|c|}{$\begin{array}{c}\text { Ликвидация голода, обеспечение продовольственной безопасности и улучшение питания и содей- } \\
\text { ствие устойчивому развитию сельского хозяйства }\end{array}$} \\
\hline 2.1 & $\begin{array}{l}\text { Доля домохозяйств, указавших при оценке своего материального поло- } \\
\text { жения на нехватку денег на еду } \\
\text { Источник: Росстат }\end{array}$ & 0,2 & 0,0 & 0,1 \\
\hline
\end{tabular}




\begin{tabular}{|c|c|c|c|c|}
\hline 3 & \multicolumn{4}{|c|}{ Обеспечение здорового образа жизни и содействие благополучию для всех в любом возрасте } \\
\hline 3.1. & $\begin{array}{l}\text { Коэффициент материнской смертности, на } 100 \text { тысяч родившихся жи- } \\
\text { выми } \\
\text { Источник: Росстат }\end{array}$ & 19,1 & 3,3 & 3,4 \\
\hline 3.2 & $\begin{array}{l}\text { Младенческая смертность (на } 1 \text { тыс. родившихся живыми) (промилле) } \\
\text { Источник: Росстат }\end{array}$ & 8,8 & 6,9 & 5,6 \\
\hline 3.3 & $\begin{array}{l}\text { Ожидаемая продолжительность здоровой жизни } \\
\text { Источник: Росстат }\end{array}$ & & 66,1 & 66,4 \\
\hline 4 & \multicolumn{4}{|c|}{$\begin{array}{c}\text { Обеспечение всеохватного и справедливого качественного образования и поощрение возможности } \\
\text { обучения на протяжении всей жизни для всех }\end{array}$} \\
\hline 4.1 & $\begin{array}{l}\text { Валовой коэффициент охвата образовательными программами высше- } \\
\text { го образования - программами бакалавриата, специалитета, магистра- } \\
\text { туры, в поцентах от численности населения в возрасте } 17-25 \text { лет } \\
\text { Источник: Росстат }\end{array}$ & - & 17,3 & 16,1 \\
\hline 5 & \multicolumn{4}{|c|}{ Обеспечение гендерного равенства и расширение прав и возможностей всех женщин и девочек } \\
\hline 5.1 & $\begin{array}{l}\text { Доля женщин на руководящих должностях } \\
\text { Источник: Росстат }\end{array}$ & & 55,3 & 56,7 \\
\hline 5.2 & $\begin{array}{l}\text { Численность прошедших переобучение и повышение квалификации } \\
\text { женщин, находящихся в отпуске по уходу за ребенком в возрасте до } \\
\text { трех лет } \\
\text { Источник: Роструд }\end{array}$ & 24 & 14 & 26 \\
\hline 6 & \multicolumn{4}{|c|}{ Обеспечение наличия и рационального использования водных ресурсов и санитарии для всех } \\
\hline 6.1 & $\begin{array}{l}\text { Доля населения, обеспеченного качественной питьевой водой из систем } \\
\text { централизованного водоснабжения } \\
\text { Источник: Роспотребнадзор }\end{array}$ & - & 69,93 & 70,26 \\
\hline 7 & \multicolumn{4}{|c|}{$\begin{array}{c}\text { Обеспечение доступа к недорогим, надёжным, устойчивым и современным источникам энергии для } \\
\text { всех }\end{array}$} \\
\hline 7.1 & $\begin{array}{l}\text { Энергоемкость валового внутреннего продукта за год, предшествующий } \\
\text { предыдущему, (кг условного топлива/ на } 10 \text { тыс.рублей, в постоянных } \\
\text { ценах } 2012 \text { года) } \\
\text { Источник: Росстат }\end{array}$ & 419,50 & 415,57 & 430,87 \\
\hline 8 & \multicolumn{4}{|c|}{$\begin{array}{c}\text { Содействие поступательному, всеохватному и устойчивому экономическому росту, полной и произ- } \\
\text { водительной занятости и достойной работе для всех }\end{array}$} \\
\hline 8.1 & $\begin{array}{l}\text { Индекс физического объема валового регионального продукта на душу } \\
\text { населения } \\
\text { Источник: Росстат }\end{array}$ & 99,9 & 99,8 & 103,1 \\
\hline 9 & \multicolumn{4}{|c|}{$\begin{array}{c}\text { Создание стойкой инфраструктуры, содействие всеохватной и устойчивой индустриализации и инно- } \\
\text { вациям }\end{array}$} \\
\hline 9.1 & $\begin{array}{l}\text { Доля исследователей в возрасте до } 39 \text { лет в общей численности россий- } \\
\text { ских исследователей } \\
\text { Источник: Росстат }\end{array}$ & 19,4 & 32,8 & 32,1 \\
\hline 9.2 & $\begin{array}{l}\text { Доля автомобильных дорог регионального или межмуниципального } \\
\text { значения, соответствующих нормативным требованиям } \\
\text { Источник: Росстат и Росавтодор }\end{array}$ & 43,5 & 48,0 & 49,5 \\
\hline 9.3 & $\begin{array}{l}\text { Доля домохозяйств, имеющих широкополосный доступ к сети «Интер- } \\
\text { нет» } \\
\text { Источник: Росстат }\end{array}$ & 74,9 & 85,9 & 83,3 \\
\hline 10 & \multicolumn{4}{|l|}{ Сокращение неравенства внутри стран и между ними } \\
\hline 10.1 & $\begin{array}{l}\text { Индекс концентрации доходов (коэффициент Джини) } \\
\text { Источник: Росстат }\end{array}$ & 0,387 & 0,378 & 0,374 \\
\hline 11 & \multicolumn{4}{|c|}{$\begin{array}{c}\text { Обеспечение открытости, безопасности, жизнестойкости и экологической устойчивости городов и } \\
\text { населённых пунктов }\end{array}$} \\
\hline 11.1 & $\begin{array}{l}\text { Доля городов с благоприятной городской средой от общего количества } \\
\text { городов } \\
\text { Источник: Минстрой }\end{array}$ & 0 & 0 & 0,28 \\
\hline
\end{tabular}




\begin{tabular}{|c|c|c|c|c|}
\hline 12 & \multicolumn{4}{|c|}{$\begin{array}{c}\text { Обеспечение перехода к рациональным моделям потребления и производства } \\
\text { (данных нет по Чеченской республике) }\end{array}$} \\
\hline 13 & \multicolumn{4}{|c|}{$\begin{array}{c}\text { Принятие срочных мер по борьбе с изменением климата и его последствиями (данных нет по субъек- } \\
\text { там РФ) }\end{array}$} \\
\hline 14 & \multicolumn{4}{|c|}{$\begin{array}{c}\text { Сохранение и рациональное использование океанов, морей и морских ресурсов в интересах устойчи- } \\
\text { вого развития (данных нет по субъектам РФ) }\end{array}$} \\
\hline 15 & \multicolumn{4}{|c|}{$\begin{array}{c}\text { Защита и восстановление экосистем суши и содействие их рациональному использованию, раци- } \\
\text { ональное лесопользование, борьба с опустыниванием, прекращение и обращение вспять процесса } \\
\text { деградации земель и прекращение процесса утраты биологического разнообразия }\end{array}$} \\
\hline 15.1 & $\begin{array}{l}\text { Індекс объёма природоохранных расходов на сохранение биоразно- } \\
\text { бразия и охрану природных территорий в\% к предыдущему году, в } \\
\text { опоставимых ценах } \\
\text { Істочник: Росстат }\end{array}$ & 92,4 & 103,1 & 97,9 \\
\hline 16 & \multicolumn{4}{|c|}{$\begin{array}{c}\text { Содействие построению миролюбивого и открытого общества в интересах устойчивого развития, } \\
\text { обеспечение доступа к правосудию для всех и создание эффективных, подотчётных и основанных на } \\
\text { широком участии учреждений на всех уровнях } \\
\text { (данных нет по субъектам РФ) }\end{array}$} \\
\hline 17 & \multicolumn{4}{|c|}{$\begin{array}{c}\text { Укрепление средств осуществления и активизация работы в рамках Глобального партнёрства в инте- } \\
\text { ресах устойчивого развития }\end{array}$} \\
\hline 17.1 & $\begin{array}{l}\text { Валовой региональный продукт на душу населения } \\
\text { Источник: Росстат }\end{array}$ & 97,4 & 98,3 & 99,6 \\
\hline
\end{tabular}

Источник: Росстат//https://rosstat.gov.ru/sdg/national

- возможность построения нелинейного динамического норматива на основе выбранных показателей.

Поясним последнее требование подробнее. Метод динамического норматива разработан И.М.Сыроежиным на основе ранговой статистики. Его применение позволяет провести обобщение разнородных показателей на основе нормативно-оценочной модели. На основе этого метода можно получить количественные уровни интегральных оценок, в нашем случае устойчивого развития региона, и факторные приросты интегральных оценок. Фактор представляется набором показателей. Факторные приросты определяются в данном случае на основе целей устойчивого развития.

3. Мониторинг устойчивого развития Чеченской республики

Мониторинг - специально организованная и постоянно действующая система сбора и анализа статистической информации, проведения дополнительных информационно-аналитических обследований и оценки состояния, тенденций развития и остроты региональных проблем. Мониторинг устойчивого развития региона осуществлялся посредством предлагаемого набора показателей (см. табл.1). Сбор данных для целей данного мониторинга проводится методом ста- тистического наблюдения Федеральной службой государственной статистики России и названных ранее ведомств. В табл. 2 представлена структура мониторинга устойчивого развития региона.

По данным за 2019-2018 гг. по Чеченской республике, представленным в табл. 1, проведён мониторинг устойчивого развития данного региона. Его результаты представлены на рис. 2.

Как видим, из представленных результатов, в развитии Чеченской республики, только один фактор - «социальное развитие», не влияет положительно, так как показатели имеют обратную динамику, все остальные факторы благоприятно влияют на достижение целей устойчивого развития. В связи с чем, можно сделать рекомендации Правительству Чеченской республики, больше внимания уделять социальным вопросам, а именно, ликвидации нищеты, голода, обеспечения продовольственной безопасности и развитию возможностей непрерывного образования. Выводы авторов подтверждает тот факт, что в стратегии социально-экономического развития Чеченской республики до 2025 года в качестве стратегической цели № 1 указана цель - «Развитие человека», которая характеризуется достижением низкого уровня безработицы и высокого уровня жизни. 


\section{Таблица 2. Структура регионального мониторинга}

\begin{tabular}{|l|l|}
\hline Цель проведения мониторинга & $\begin{array}{l}\text { Сбор информации, выявление имеющихся проблем устойчивого развития } \\
\text { региона и принятие на основании полученных данных стратегических } \\
\text { решений }\end{array}$ \\
\hline Объект мониторинга & $\begin{array}{l}\text { Устойчивое развитие региона в соответствии с целями, представленными } \\
\text { на рис. } 1\end{array}$ \\
\hline $\begin{array}{l}\text { Субъекты организации } \\
\text { проведения мониторинга }\end{array}$ & $\begin{array}{l}\text { Субъектами мониторинга устойчивого развития являются носители мони- } \\
\text { торинговых функций Их условно можно разделить на две группы: } \\
\text { - субъекты, которые предоставляют информацию (названы ранее); } \\
\text { - субъекты, которые собирают и обрабатывают информацию (территори- } \\
\text { альный орган федеральной службы государственной статистики России). }\end{array}$ \\
\hline Методы сбора информации & Статистическое наблюдение \\
\hline Критерии мониторинга & $\begin{array}{l}\text { Оптимальность, достижимость, адекватность, точность, объективность, } \\
\text { достоверность, однозначность, экономичность, сопоставимость, своевре- } \\
\text { менность }\end{array}$ \\
\hline
\end{tabular}

Источник: разработка авторов

\section{Факторы-цели устойчивого развития региона}

\begin{tabular}{|c|}
\hline Социальное развитие \\
\hline Повсеместная ликвидация нищеть \\
\hline $\begin{array}{c}\text { Ликвидация голода, обеспечение } \\
\text { продовольственной безопасности и } \\
\text { улучшение питания и содействие } \\
\text { устойчивому развитию сельского } \\
\text { хозяйства }\end{array}$ \\
\hline $\begin{array}{c}\text { Обеспечение здорового образа } \\
\text { жизни и содействие благополучию } \\
\text { для всех в любом возрасте }\end{array}$ \\
\hline $\begin{array}{c}\text { Обеспечение всеохватного и } \\
\text { справедливого качественного } \\
\text { образования и поошрение } \\
\text { возможности обучения на } \\
\text { протяжении всей жизни для всех }\end{array}$ \\
\hline $\begin{array}{c}\text { Гражданско-правовое } \\
\text { развитие }\end{array}$ \\
\hline $\begin{array}{c}\text { Обеспечение гендерного равенства и } \\
\text { расширение прав и возможностей } \\
\text { всех женщин и девочек }\end{array}$ \\
\hline $\begin{array}{c}\text { Сокращение неравенства внутри } \\
\text { стран и между ними }\end{array}$ \\
\hline
\end{tabular}

\begin{tabular}{|c|}
\hline Экономическое развитие \\
\hline \hline Обеспечение доступа к недорогим, \\
надёжным, устойчивым и \\
современнымм источникам энергии \\
для всех \\
\hline Содействие поступательному, \\
всеохватному и устойчивому \\
экономическому росту, полной и \\
производительной занятости и \\
достойной работе для всех \\
\hline \begin{tabular}{c} 
Укрепление средств осуществления \\
и активизация работы в рамках \\
Глобального партнёрства в \\
интересах устойчивого развития \\
\hline Инновационное и цифровое \\
развитие \\
\hline Создание стойкой инфраструктуры, \\
содействие всеохватной и \\
устойчивой индустриализации и \\
инновациям
\end{tabular} \\
\hline
\end{tabular}

\begin{tabular}{|c|}
\hline Экологическое \\
развитие \\
\hline Обеспечение наличия и \\
рационального \\
использования водных \\
ресурсов и санитарии для \\
всех \\
\hline Обеспечение открытости, \\
безопасности, \\
жизнестойкости и \\
экологической \\
устойчивости городов и \\
населённых пунктов \\
\hline Защита и восстановление \\
экосистем суши и \\
содействие их \\
рациональному \\
использованию, \\
рациональное \\
лесопользование, борьба \\
с опустыниванием, \\
прекращение и \\
обращение вспять \\
процесса деградации \\
земель и прекращение \\
процесса утраты \\
биологического \\
разнообразия \\
\hline
\end{tabular}

Рисунок 2. Мониторинг достижения целей устойчивого развития

Чеченской республики по факторам (разработка авторов)

Примечание: курсивом выделены факторы и цели, в достижении которых существуют проблемы 


\section{Библиографический список}

1. Доклад ООН «Цели развития тысячелетия за 2015 г.» [Электронный ресурс]: https://www.un.org/ru/ millenniumgoals/mdgreport2015.pdf (дата обращения 19.07.21).

2. Официальный сайт ООН[Электронный ресурс]: https://www.un.org/sustainabledevelopment/ru/about/ development-agenda/(дата обращения 19.07.21).

3. Официальный сайт Федеральной службы государственной статистики России [Электронный ресурс]: https://rosstat.gov.ru/sdg/national (дата обращения 19.07.21).

4. Доклад «Цели устойчивого развития: ООН и Россия»// Под редакцией С.Н.Бобылева, Л.М.Григорьева, 2016 г.с.3. [Электронный ресурс]: https://ac.gov.ru/archive/files/publication/a/14684.pdf (дата обращения 19.07.21).

5. Иванов Ю.Н. История возникновения и развития Системы национальных счетов // Вопросы статистики.2012.- № 8.- C. 79-83. С.80.

6. Nordhaus W., Tobin J. Is Growth Obsolete? / The National Bureau of Economic Research [Электронныйресурс]. Режим доступа: http://www.nber.org/chapters/c7620.pdf(дата обращения 19.07.21).

7. Белоновская А.Н., Джавадова С.А., Погудаева М. Ю. К вопросу о необходимости реформирования системы национальных счетов для оценки благосостояния и устойчивости развития в современных условиях/Вестник экономической безопасности. № 2, 2016. С.281-283. С.283.

8. Kubiszewski I, Costanza R., Franco C., Lawn F., Talberth J., Jackson T., Aylmer C. Beyond GDP: Measuring and achieving global genuine progress // Ecological Economics № 93, 2013., p. 57-68.

9. [Электронный ресурс]: https://www.un.org/ru/ga/pdf/brundtland.pdf(дата обращения 19.07.21). C 423.

10. Рекомендации Конференции европейских статистиков для измерения устойчивого развития// Организация Объединенных Наций Нью-Йорк и Женева, 2014.

11. Стратегия развития Чеченской республики до 2025 г. [Электронный ресурс]: http://economy-chr.ru/content/ uplod/C.90(дата обращения 19.07.21). 